\title{
Demystify Criticality in Academic Assignment Writing: A Comparative Text Analysis
}

\author{
Huifang $\mathrm{Liu}^{1}$, Yong $\mathrm{Mei}^{2} \&$ Haitang Zhou ${ }^{3}$ \\ ${ }^{1}$ School of Foreign Studies, Huanggang Normal University, Huanggang, China \\ ${ }^{2}$ School of Foreign Languages, Hubei University, Wuhan, China \\ ${ }^{3}$ College of Foreign Languages, Hainan University, Haikou, China \\ Correspondence: Huifang Liu, School of Foreign Studies, Huanggang Normal University, Huanggang, China. Tel: \\ 86-0713-862-1617. E-mail: 530427409@qq.com
}

Received: June 24, 2015 Accepted: July 25, 2015 Online Published: September 29, 2015

doi:10.5539/ijel.v5n5p83 URL: http://dx.doi.org/10.5539/ijel.v5n5p83

\begin{abstract}
Based on a small corpus, this study investigates how "criticality", a core requirement of academic assignment writing, is constructed by linguistic resources. The method of Rich Feature Analysis was adopted to explore how language resources are mobilized to synthesize and evaluate to achieve criticality, specifically, Theme choice, thematic progression pattern, hyper-Theme and reporting style. The analysis revealed that the stronger essay demonstrates expertise in manipulating different types of Themes, showing a clear logical pattern of Theme progression and a clear overall organization through utilization of hyper-Themes. It also mainly employs non-reporting style to enable evaluation of references. By making the linguistic realization of criticality explicit, this study helps novice writers better understand criticality, and informs writing teachers in academic writing.
\end{abstract}

Keywords: academic writing, criticality, projection, rich feature analysis, Themes

\section{Introduction}

Academic assignment writing, as one of the most crucial yet demanding surviving skills for graduate students, is always confusing and confounding in terms of its requirements and assessing criteria. At the core of its requirements and assessing criteria is the issue of "criticality", a term which is ubiquitous from the top of the lecturers' tongue to the margin of the students' assignments. High-stakes though it is, "criticality" is never really clarified; consequently students often feel lost when it comes to assignment writing or comment reading. To address this problem, this essay aims to demystify "criticality" by investigating how "criticality" is constructed by linguistic resources in academic assignment writing.

To start with, the concept of "criticality" needs to be defined. Criticality in academic writing is often taken as "critical thinking skills", which can be further broken down into sub-skills such as synthesizing, questioning and challenging, evaluating, formulating and presenting positions, etc. (Paltridge, 2007; Webster, 1989). These critical skills, from the perspective of SFL (Halliday, 1994), fall into two categories: one is textual skills (like synthesizing), the other is interpersonal skills (like evaluating). Given that synthesizing is the fundamental textual skill that contributes to the logical organization and development of the text, while evaluation is the underlying interpersonal skill that accounts for authors' appreciation of previous literature, the synergy of synthesizing and evaluation reveals the truth of "criticality" on both the level of mode and tenor (Halliday, 1994) in academic writing.

To explore how language resources are mobilized to synthesize and evaluate so as to achieve criticality in academic writing, the method Rich Feature Analysis is adopted (Barton, 2004). This method is proved to be particularly useful in academic discourse analysis, especially in the analysis of student writing (Barton, 2004).

To embark on our exploration, a small study corpus of two assignment essays written by two members of PGDELT (Post-graduate Diploma for English Language Teaching which is a Singapore-government-sponsored scheme for Chinese EFL Teachers to receive in-service training at National Institute of Education at Nanyang Technological University) for the course Teaching Listening and Speaking is established (Assignment instruction and evaluation comments for the two essays are given in Table 1). These two literature review essays are graded respectively as A (hereafter as stronger essay) and B- (weaker essay) by two lecturers at NIE according to the 
"criticality" criterion. The stronger essay is commented as a "critical appraisal", while the weaker essays is commented as "describing rather than reviewing". This categorization in text selection is a popular practice in composition study (Barton, 2004). Besides, the selection of two extreme essays assessed against the "criticality" criterion is believed to be optimal in discovering the contrast in linguistic choices.

SFL is also drawn on for the study of linguistic resources that address "criticality" on the level of textual and interpersonal. Some potential areas are to be explored: Theme choice, thematic progression pattern, hyper-Theme and reporting style.

\section{Theme Choices}

The first language feature under investigation is theme choice. Themes are the initial elements of clauses or clause complexes and together with the Rheme (the rest of the clause). They make up the entire clause or clause complex. One way the Theme choices made at the beginning of a clause are significant is that they create the framework for the interpretation of the rest of the clause, or in another word, the starting point of the clause indicates the perspective the writer is taking (Hewings, 2005). Appropriate theme choices enable the writer to foreground the messages from the clauses to build up the logic flow in textual development, which is highly valued in a critical literature review.

For analytical purposes, Theme choices in the two texts are explored both quantitatively and qualitatively following the categorization based on Halliday (1994): unmarked topical Theme, interpersonal Theme, textual Theme, marked Theme and multiple Theme.

The following table shows the number and percentage of clauses that consisted of single element Themes and multiple Themes which comprised those with textual and those with interpersonal across the two texts respectively.

Table 1. Theme patterning in the two texts

\begin{tabular}{llllll}
\hline \multirow{2}{*}{ No. of clauses } & \multicolumn{2}{l}{ Single element Theme } & Multiple Theme & \\
\cline { 3 - 6 } & $\begin{array}{l}\text { Unmarked } \\
\text { Topical }\end{array}$ & Marked & $\begin{array}{l}\text { Multiple with } \\
\text { Textual }\end{array}$ & $\begin{array}{l}\text { Multiple with } \\
\text { Interpersonal }\end{array}$ \\
\hline S & 71 & $28(39.4 \%)$ & $10(14.1 \%)$ & $34(47.9 \%)$ & $9(12.7 \%)$ \\
W & 91 & $47(51.6 \%)$ & $16(17.6 \%)$ & $27(29.7 \%)$ & $2(2.2 \%)$ \\
\hline
\end{tabular}

Note. $\mathrm{S}=$ stronger text, $\mathrm{W}=$ weaker text.

The most obvious areas of contrast are in the use of unmarked topical and multiple Themes. The writer of the weaker text makes use of $12.2 \%$ more unmarked topical Themes than does the writer of the stronger text, who in contrast, uses $18.2 \%$ more textual Themes and $10.5 \%$ more interpersonal Themes. In discussing the results, we attempt to examine Theme choices, especially the increasing use of multiple Themes which can tell about criticality in literature review writing.

\subsection{Unmarked Topical Themes}

In the weaker text, there is an extensive use of unmarked topical Themes where subject and Theme identifying people, things or abstract qualities are conflated. The example below is a paragraph taken from the weaker text: 
Table 2. Topical Themes in the weaker text

\begin{tabular}{|l|l|}
\hline Appropriate use of the listening strategies / can enhance learners' & Topical \\
listening proficiency, especially the metacognitive strategies, which / & Topical \\
can unconsciously develop learners' ability to use appropriate strategies & \\
and raise their awareness of listening as a process. Nathan / (2008) has & Topical \\
explored that in listening tasks / collaboration / impeded a positive & Marked / topical \\
influence on the learners' development and understanding of & \\
metacognitive knowledge about listening. Goh / (2008) combined the & Topical \\
person, task and strategic knowledge with planning, monitoring and & \\
evaluating, and / then / formed metacognitive instruction, & Textual / textual \\
which / has been researched by many scholars. & $\begin{array}{l}\text { Topical } \\
\text { Based upon statistics, / the study made by Vandergrift (2007) / shows } \\
\text { that metacognitive instruction / greatly improves learners' listening }\end{array}$ \\
performance & Topical \\
\hline
\end{tabular}

Note. The whole Theme is italicized. The '/' is used to separate different types of Theme element.

This paragraph is under the subheading "Practical application", indicating the writer is supposed to evaluate and comment on the application of metacognitive instruction defined in the previous section. However, the writer deviates this requirement and only reports several researchers' exploration on this approach without any evaluation. Most reporting sentences initiate with the name of the researcher as topical Themes, indicating that the writer is describing what the researchers did in the particular field. This can contribute to texts sounding descriptive or expository (Hewings, 2005) and partly explains the supervisor's comment that the writer is not critical enough.

In contrast to the pervasive use of topical Themes in the weaker text, the stronger one has more varied Theme choices, especially a wide range of multiple Themes, which not only demonstrates the writer's familiarity with the research in this field, but also shows that she is able to interpret and evaluate the relevant research positively or negatively rather than just recount what is going on in the research field. Such capacity traced in the use of multiple Themes will be elaborated in the following section.

\subsection{Multiple Theme}

The stronger text uses much more multiple Themes, specifically an increase of $18.2 \%$ of textual and $10.5 \%$ of interpersonal. The following paragraph demonstrates the significance of multiple Themes in building up coherent organization and the writer's argument:

Table 3. Theme choices in the stronger text extract

\begin{tabular}{|l|l|}
\hline Despite the inconclusive findings so far, / practitioners / are interested in & Marked / Topical \\
"designing and implementing instructional programs to promote strategy & \\
development and use", especially for less proficient listeners (Cross, & \\
2009, p. 154). Therefore,/ practical application of strategy instruction/ & Textual / Topical \\
chiefly focuses on guidelines and principles in its actual implementation, & \\
and certain common points have been identified. & \\
First,/ preference in listening strategy instruction / was chiefly given to & Textual / Topical \\
those that are involved in top-down processes, even though those & \\
involved in bottom-up processes were also taken into account (Cross, & \\
2009, p. 154). Second, / meta-cognitive strategy / was unanimously & Textual/Topical \\
included within strategy instructional programs due to the fact that it has & \\
been found to be "vital for effective comprehension" (Rubin, Chamot and & \\
Anderson, 2007, p. 182), even though / all the three types of learning & Textual/Topical \\
strategies / need to be taught and practiced (Mendelsohn, 2006, p. 80). & \\
\hline
\end{tabular}

At the very beginning, the marked Theme "Despite the inconclusive findings so far" retrospects the writer's criticism of previous research and prospects her affirmative stance to the practical application of listening strategy instruction. In what follows, several textual Themes (Therefore, First, Second, even though) are used not only to push the discourse forward, but also highlight logical connection. This is particularly important in 
building up argument, insight, criticism, discussion and analysis in academic writing (Hewings, 2005). Such skillful use of multiple Themes is not frequently seen in the weaker text. The following is an extract taken from it.

Table 4. Theme choices in the weaker text extract

\begin{tabular}{l|l|l}
\hline Metacognitive strategy / might be the most studied among the three & Topical \\
categories. It / is defined by Chamot (1995, p. 15) as "executive processes & Topical \\
associated with the regulation and management of learning, and include & \\
strategies used to plan for a task, to monitor a task in progress, and to evaluate & \\
the success of a task after its completion". It / functions as an approach to & Topical \\
"manage and facilitate mental process and cope with difficulties during & \\
listening" (Goh, 2002, p. 7). The metacognitive processes / proposed by & Topical \\
Vandergrift (2004) give the learners insight into the strategies they should & \\
employ while listening and also help them integrate the strategies as a whole. &
\end{tabular}

This extract discusses "metacognitive strategy" in terms of its definition, function and processes involved. The repeated use of almost the same topical Theme contributes to the descriptive rather than evaluative feature of the text and indicates the writer's lack of capability of text building and logic connection.

Another contrast of the two texts lies in the use of interpersonal Themes. The following examples contain the use of interpersonal Themes (in bold) found in the stronger text:

- Generally speaking, three main types of listening strategies have been widely documented in the relevant literature.

- However, due to the small number of empirical studies so far and the inconsistent findings they have reported, it cannot be confidently concluded that "this kind of strategy training works" (Field, 1998, p. 115).

- Therefore, it is believed that listening strategy instruction will be effective in promoting students' learning ability in the long run.

- Besides, it will also be feasible to implement such instructional program in view of the number of instructional programs that have been conducted (Seo, 2000).

In the first, the interpersonal Theme element "Generally speaking" conveys the writer's synthesis and mediates the amount of commitment it shows to the statement. In the second, the writer expresses her negative evaluation upon the effectiveness of strategy training in a modest way by saying "it cannot be confidently concluded", while in the third, "it is believed" makes her opinion sound more objective without attributing it to the author or anyone else. In the last sentence, the writer expresses her support for a certain instructional program. In a nutshell, by presenting the writer's angle on the matter in the clause at a salient position with these interpersonal Themes, the writer is prepared to intrude more openly into the text rather than in a disguised, objectivized way. Therefore the rhetorical role of the text is more visible (Hewings, 2005). It is the presences of these interpersonal elements which help build up the evaluative and persuasive nature of the literature review genre.

The analysis presented suggests that Theme as a useful lexico-grammatical indicator reflects how writers rhetorically frame their critical essays. The predominance of unmarked topical Themes in the weaker text resulted in an essay more like a recount or description rather than critique or evaluation, which explains the comment made by the lecturer, "You are describing rather than reviewing". In contrast to the weaker text, the stronger is logically more organized and this is shown quantitatively in the Theme choices. The increased use of multiple Themes means that the writer of the stronger text can exploit Theme position to signal logical connection or his/her particular stance on the matter at issue, thus build up criticality textually and interpersonally within the clause level.

\section{Thematic Progression}

To further exploit the potential of Theme in constructing logical synthesis above clause level, thematic progression pattern is examined. Thematic progression refers to the way in which the Theme of a clause may pick up, or repeat, a meaning from a preceding Theme or Rheme (Paltridge, 2006). This function of thematic progression makes it another key way to observe the information flow created in a text. Such function makes it an important indicator of criticality in literature review if we take into account that logic connection is an important aspect of criticality in literature review writing. Therefore, investigating thematic progression is 
meaningful in comparing the two target texts. The following figure shows the thematic progression of the stronger text.

Table 5. Thematic progression in stronger text extract

\begin{tabular}{|c|c|c|}
\hline \multicolumn{2}{|r|}{ Theme } & Rheme \\
\hline Theme 1 & $\begin{array}{l}\text { Second, positive findings from } \\
\text { empirical studies }\end{array}$ & $\begin{array}{l}\text { have provided strong proofs about the } \\
\text { effectiveness of listening strategy } \\
\text { instruction. }\end{array}$ \\
\hline Theme 2 & $\begin{array}{l}\text { Although empirical strics about the } \\
\text { effectistening strategy instruction }\end{array}$ & have produced mixed results, \\
\hline Theme 3 & $\begin{array}{l}\text { a deeper analysis of the research } \\
\text { designs and methodologies used in } \\
\text { those studies }\end{array}$ & $\begin{array}{l}\text { helps to uncover the reasons for the } \\
\text { absice of positive results. }\end{array}$ \\
\hline Theme 4 & $\begin{array}{l}\text { Factor such as short intervention } \\
\text { time, inexperienced teacher in } \\
\text { instructional program, and the use of } \\
\text { quantitative research instruments }\end{array}$ & $\begin{array}{l}\text { have jointly hindered the emergence of } \\
\text { positive results. }\end{array}$ \\
\hline
\end{tabular}

As illustrated, the subject matter in Rheme 1 is taken up in the Theme of the following clause. In the same vein, the message in Rheme 3 is picked up at the beginning of the next clause. Such a pattern of thematic progression resembles a zig-zag linear pattern, which allows an element that is first introduced as new information to become the theme of the following (Paltridge, 2006). It is an important resource purposefully drawn by the writer to achieve logical organization both in meaning and in structure. Moreover, it orients readers to the point that is going to be developed in the paragraph (Paltridge, 2006). By contrast, the example below (see Table 6) taken from the weak text demonstrates different ways to present information that are not easy to pattern.

Table 6. Thematic progression in weaker text extract

\begin{tabular}{|c|c|c|c|}
\hline \multicolumn{2}{|r|}{ Theme } & \multicolumn{2}{|r|}{ Rheme } \\
\hline Theme 1 & $\begin{array}{l}\text { According to J. R. Anderson } \\
\text { (1995), listenjing }\end{array}$ & Rheme 1 & $\begin{array}{l}\text { is a comprehension process and consists of } \\
\text { three levels of processing: perception, parsing } \\
\text { and utilization, }\end{array}$ \\
\hline Theme 2 & which & Rheme 2 & $\begin{array}{l}\text { serve a cognitive model for listening } \\
\text { comprehension. }\end{array}$ \\
\hline Theme 3 & $\begin{array}{l}\text { For listners, background } \\
\text { knowledge, nowledge of situation } \\
\text { and co-text and knowledge of the } \\
\text { language sysłem }\end{array}$ & Rheme 3 & $\begin{array}{l}\text { are considered the three essential sources of } \\
\text { information in listening comprehension } \\
\text { (Anderson \& Lynch, 1988). }\end{array}$ \\
\hline Theme 4 & And the listching process & Rheme 4 & focuses mainly on meaning not form. \\
\hline Theme 5 & $\begin{array}{l}\text { In the discussion of L2 listening, } \\
\text { "bottgm-up" and "top down" }\end{array}$ & Rheme 5 & $\begin{array}{l}\text { are usually regarded as the two important } \\
\text { concepts of listening process. }\end{array}$ \\
\hline Theme 6 & "Botop-up" & Rheme 6 & $\begin{array}{l}\text { refers to that the processing is built from the } \\
\text { small units to larger ones, }\end{array}$ \\
\hline Theme 7 & and "toptown" & Rheme 7 & $\begin{array}{l}\text { is the process built from the larger units to } \\
\text { small ones. }\end{array}$ \\
\hline Theme 8 & $\begin{array}{l}\text { In the restearch made by Hulstijn } \\
\text { (2003), "bo'tom-up" }\end{array}$ & Rheme 8 & $\begin{array}{l}\text { is connected with multimedia software } \\
\text { offering three listening modes for listeners to } \\
\text { concentrate the separate units or short chunks } \\
\text { first and then combine them and interpret the } \\
\text { meaning of what they hear. }\end{array}$ \\
\hline
\end{tabular}

Note. dotted arrows=information indirectly picked up.

Except the last three Themes which pick up some message previously presented, most other Themes come up with unexpected new information which is not logically contextualized, thus making it hard to relate to the direct 
context or to predict what is going to emerge. Consequently readers may easily lose track of the information flow with such unknown starting points. Cases like this are not rare in the weaker essay.

As shown above, thematic progression pattern is a resource for constructing logical predictability within and between clauses in the close context. To explore even further in Theme, we need to go to the level of paragraph and above to see how text are developed and organized. This goal brings us to hyper-Theme.

\section{Hyper-Theme}

Hyper-Theme is a term to account for one particular pattern of Theme-Rheme progression (Danes, 1974, cited in Ravelli, 2005), which is "An extension of the general principle of thematic organization in text" (Halliday, 1994; cited in Ravelli, 2005, p. 112), and also "one of the main resources for signaling and foregrounding the conceptual framework of an essay" (ibid.).

Hyper-Themes provide the issues/ideas that will predominate within the paragraph. As Martin specifies (1992), a hyper-Theme is an introductory sentence or group of sentences to predict a particular pattern of interaction among lexical strings, reference chains and Theme selection in following sentences. Regarding the places of hyper-Themes, according to Ravelli (2005), they are not confined to the beginning of a paragraph but also other places, i.e., "a structural place, a step in the argument" (p. 115).

As one resource to signal and highlight conceptual argumentation, hyper-Themes mainly contribute to the establishment of expansion, one type of the two major logico-semantic relations in Halliday and Matthiessen's term (1999). In expansion, one clause expands on the meaning of another in various ways. For example, the second clause below adds specification concerning the reason for a difficult test to the first one:

This test is very difficult; it's too long and has many questions that we haven't discussed in class.

Expansion can be further divided into three semantic groupings: elaboration, extension and enhancement, which refer to different clausal relations and are symbolized by various signs for the sake of clearer presentation. A table is used to illustrate its detailed categorization based on Ravelli' s (2005) description.

Table 7. Categorization of expansion

\begin{tabular}{lll}
\hline Categories & Definitions & Signs for symbolization \\
\hline $\begin{array}{l}\text { Elaboration(that } \\
\text { is to say } \\
\text { relationship) }\end{array}$ & $\begin{array}{l}\text { One clause does not add any essentially new elements } \\
\text { to the message, but gives more information about what } \\
\text { is already there, such as relating to whole or part of the } \\
\text { message, restating, clarifying or exemplifying. }\end{array}$ & symbolized by "=" \\
$\begin{array}{l}\text { Extension: (and, } \\
\text { but, or }\end{array}$ & $\begin{array}{l}\text { One clause extends another by simple addition (the } \\
\text { relationships) }\end{array}$ & symbolized by "++" relation) or by replacement (the "or" relation). \\
$\begin{array}{l}\text { Enhancement: } \\
\text { so, yet, then } \\
\text { relationship) }\end{array}$ & $\begin{array}{l}\text { One clause expands another by embellishing around it: } \\
\text { qualifying it with some circumstantial features of time, } \\
\text { place, cause or condition }\end{array}$ & symbolized by "×" \\
\hline
\end{tabular}

As aforementioned, expansion as one type of the logico-semantic relations could be applied at the level of paragraph, not just at the level of clauses. We single out the hyper-Theme from the themes in each paragraph as the place of hyper-Themes is "a structural place, a step in the argument" (Ravelli, 2005, p. 115).

Appendix B presents a dynamic view of the organizational relations to reveal how one step in the argument leads to another and to highlight possible strength in the stronger essay. As illustrated, elaborations and extensions are two predominant semantic relations in the stronger essay.

In terms of overall organization, extension is the major subtype of logico-semantic relations running throughout the whole essay, and marvelously, almost every first hyper-Theme (shortened as HT) completely corresponds with the introductory sentence of beginning paragraph in each section. Specifically, it can be seen that HT3 (Para 2) starts Section 2 (Para 2), HT6 with the beginning paragraph (Para 3) in Section 3 (Para 3-5), HT13 with Para 6 in Section 4 (Para 6-9), HT21 with Para 10 in Section 5 (Para 10-13) and HT25 with Para 14 in Section 6 (Para 14-16).

In contrast, hyper-Themes in each paragraph are largely elaborating relations, with one hyper-Theme as the core being supported by the rest ones. For instance, in Para 2 also Section 2, HT 3 is specified and supported by HT 4 
and 5 (see Figure 1).

\section{=Р2T3: Theoretical focus}

=T4: ultimate goal

=T5: three main types

Figure 1. The first case of hyper-Theme relations

The first paragraph P1 contains two parallel hyper-Themes, with HT1 introducing the topic and contextualizing: Process-based approach to listening instruction focuses on meaning construction through the interaction of both top-down and bottom-up processing, with HT2 serving as thesis statement that only discussion of process-based approach to listening instruction into listening strategy instruction is to be presented. Both two hyper-Themes work together to fulfill two requirements of literature review for "establishing the context of the topic or problem" and "rationalizing the significance of the problem" (Hart, 1998, p. 2) (see Figure 2).

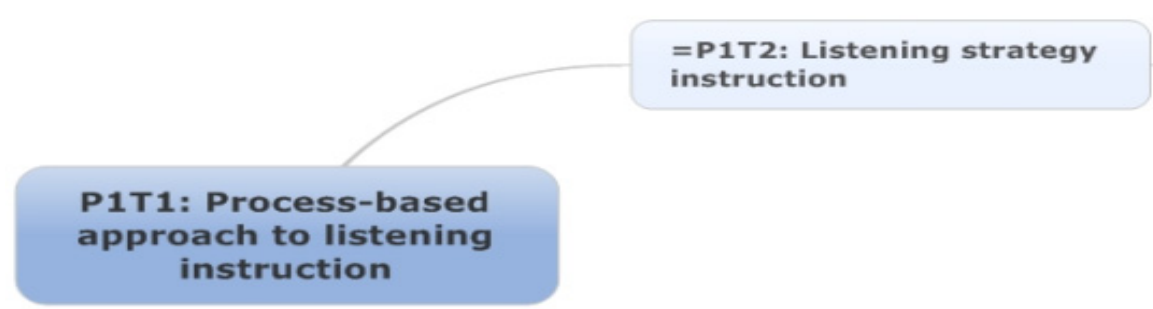

Figure 2. The second case of hyper-Theme relations

Elaborating relations can be seen between hyper-Themes in Paragraph 1 and those in Paragraph 2. As a specification of HT 2, HT 3 in Paragraph 2 introduces necessary theoretical framework to pinpoint theoretical focus of listening strategy instruction, while the following two hyper-Themes serve to explain the ultimate goal and three major types of that theoretical focus.

HT 6 in the beginning paragraph of Section 3 has an extending relation with HT 3 in Section 2 (see Figure 3), because it initiates a series of related research of listening strategy instruction which are parallel to theoretical discussions in previous section.

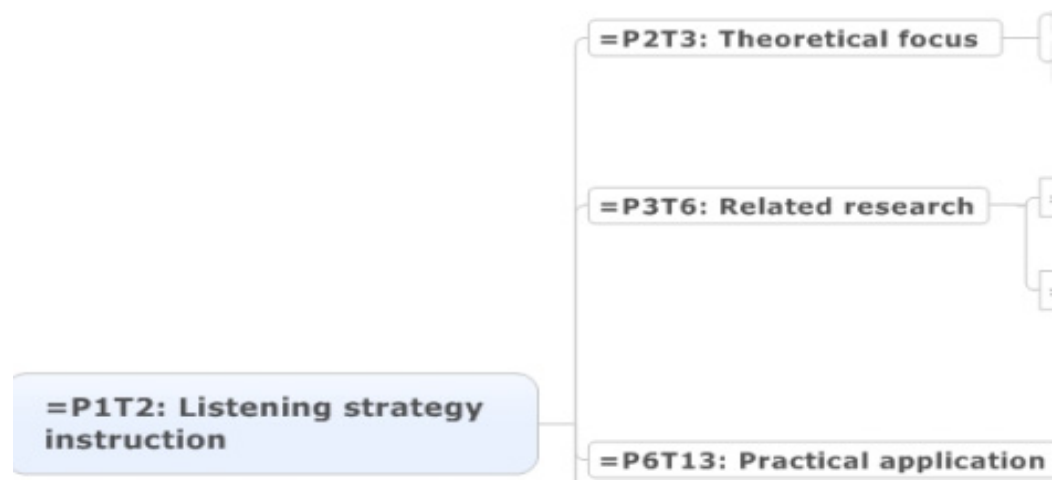

Figure 3. The third case of hyper-Theme relations

For the rest hyper-Themes within the section, TH 7 and TH12 are supporting TH 6 to cover and criticize the findings of related empirical studies. To consolidate her argumentation, the writer has again employed another four hyper-Themes (HT 8-11) which synthesize and evaluate four major categories of findings of empirical studies (see Figure 4). 


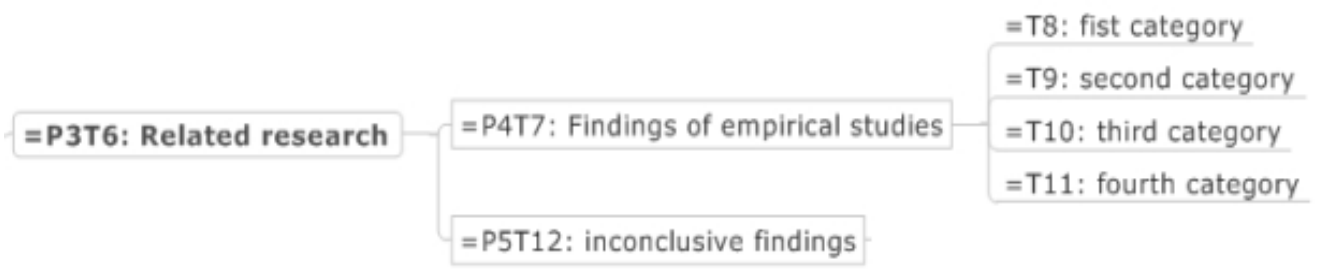

Figure 4. The fourth case of hyper-Theme relations

This skillful maneuver of hyper-Themes has substantially explained the high grading of this essay because "synthesizing claims and support from a range of sources and evaluating them" are two essential component of critical thinking in academic writing (Mohan, 1986; 1990; Vygotsky, 1962; Widdowson, 1990; cited in Pally, 2001, p. 279). Using her understanding, synthesis, and questions as a basis, the writer continues to discuss the inclusiveness or weakness of current empirical studies in TH12 to formulate her own ideas about listening strategy instruction: "It cannot be confidently concluded that this kind of strategy training works." As Pally (2001) argues, this formulation of one's own ideas is highly desirable.

It is marvelous to see that this extending relation between hyper-Themes in different sections and elaborating relation within one section occur in the rest part of the essay. For instance, in the last section (Section 6), HT 25 has extending relation with HT21 in previous section (Section 5) whereas, HT 22-24 in the same section are all detailed explanations or exemplifications to HT 21. (See Figure 5)

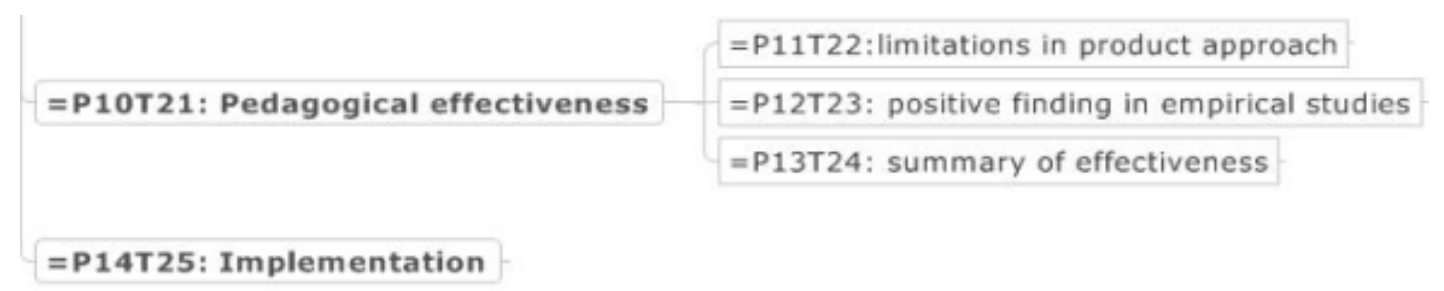

Figure 5. The fifth case of hyper-Theme relations

As far as the weaker essay is concerned, initial analysis has demonstrated that the hyper-Themes are messily connected between paragraphs, so it is not easy to clearly illustrate their links like what has been done with the stronger one.

In a word, the stronger essay has been characterized by clear overall organization at the level of paragraph and text through the skillful utilization of hyper-Themes, which enables information organization and development into a logical synthesis.

By now, we have fully exploited Theme on all levels (clause, paragraph and text). The linguistic resources of Theme, thematic progression pattern and hyper-Theme employed by the stronger and the weaker essay clearly demonstrate the potential of Theme in "synthesizing" (information organization and textual development) which constitutes one major component of criticality in academic writing. While "synthesizing" is driven by logical-semantic "expansion", another component of criticality "evaluation" is realized through logical-semantic "projection".

\section{Projection}

"Projection" is another type of logical-semantic relation defined by Halliday and Matthiessen (1999) other than "expansion" (as discussed in the previous sections). According to Thompson (2004), "projection" refers to the clausal relationship of one clause serving another as "second-order" use of language (similar to the traditional concept "reported speech"). This type of relationship carries equally significant weight as "expansion" in academic writing. While "expansion" enables clause-building and text development into a logical synthesis; "projection" allows reporting as well as evaluation of literature.

The potential of "projection" in academic writing can be realized in three major reporting styles (Swales,1990): central (where an author is reported as responsible for the finding or argument and is placed in the subject position, as in "Burke (1986) discovered that many students would like to become integrated into Australian 
society."), non-central (where an author is reported as responsible for the finding or argument, but the author's name is placed in brackets at the end of the sentence, as in "It has been shown that students have often performed successfully in their own education system before they seek entry to the particular university (Ballard, 1991).") and non-reporting (where the results of a piece of research are presented with less focus being given to the author or the actual study and no 'reporting verbs' such as 'claim' or 'shown' are used, as in "Instead of motivation producing achievement, it may be that achievement produces motivation (Spolsky, 1989)."

Exploring into the reporting styles of the two student essays reveals significant difference in reporting frequency and distribution of reporting styles (See Table 8). In reporting frequency, the stronger essay is dense with one instance of reporting every 1.78 clauses on average, while the weaker essay is sparse with one instance of reporting every 3.80 clauses. In distribution of reporting styles, the dominant reporting style in the stronger essay is non-reporting $(67.5 \%)$, while in the weaker essay is central reporting $(62.5 \%)$. The relatively less used reporting styles in the stronger essay are non-central reporting $(20 \%)$ and central reporting $(12.5 \%)$, while in the weaker essay are non-reporting (25\%) and non-central reporting (12.5).

Table 8. Reporting styles

\begin{tabular}{lllllll}
\hline & $\begin{array}{l}\text { Central } \\
\text { reporting }\end{array}$ & $\begin{array}{l}\text { Non-central } \\
\text { reporting }\end{array}$ & Non-reporting & $\begin{array}{l}\text { Total } \\
\text { reporting } \\
\text { instances }\end{array}$ & $\begin{array}{l}\text { Total } \\
\text { clauses }\end{array}$ & $\begin{array}{l}\text { Clause No. } \\
\text { /reporting instance }\end{array}$ \\
\hline $\begin{array}{l}\text { The stronger } \\
\text { essay }\end{array}$ & 5 & 8 & 27 & 40 & 71 & 1.78 \\
$\begin{array}{l}\text { Percentage } \\
\text { The weaker }\end{array}$ & $12.5 \%$ & $20 \%$ & $67.5 \%$ & $100 \%$ & $/$ & $/$ \\
$\begin{array}{l}\text { essay } \\
\text { Percentage }\end{array}$ & 15 & 3 & 6 & 24 & 91 & 3.80 \\
\hline
\end{tabular}

It is generally recognized that reporting and evaluating on previous research is a central part of academic writing, especially for literature review (Paltridge \& Starfield, 2007). The academic convention of building argument on established theories, research findings and claims, determines the extensive citing of references in academic writing.

The large amount of citation in the stronger essay (40 instances in 71 clauses) suggests the author's awareness of the academic convention of grounding one's argument on a firm basis of literature. The weaker essay (24 instances in 91 clauses), on the contrary, indicates an unfamiliarity with the convention.

Also the interesting finding in reporting preference that the stronger essay favors non-reporting and the weaker essay favors central reporting demonstrates different handling of citations.

According to the definition of the three major reporting styles (Swales, 1990) mentioned at the beginning of this section, author's responsibility decreases and writer's responsibility increases along with the shifting of reporting style from central reporting, to non-central reporting to non-reporting. Therefore, by adopting non-reporting style, the writer backgrounds the source of research finding along with the author's responsibility on the research finding, and foregrounds the writer's responsibility and stance on the research finding.

As shown in Excerpt 1.1, while the author is making claims on the "inconsistency" found in "instruction programs", each claim is supported with a non-reporting citation, whereby author's responsibility is played down, and the writer's stance is formulated by packing and integrating the literature into the writer's own argument. This is an effective strategy of synthesizing and evaluating literature. Although non-reporting style does not guarantee critical synthesis of literature, its shift of focus from literature source to upper-level integration of reference makes it possible to be critical. Meanwhile it helps avoid the common "uncritical" problem of making a "shopping-list" out of the literature, which is most likely to happen with central-reporting and non-central reporting styles.

\section{Excerpt 1.1 Non-reporting in the stronger essay}

While the above two points are commonly adopted practices in listening strategy instructional program, there are also areas where inconsistency were found among those programs. First, few instructional programs have demonstrated "how strategies have been tailored to meet learners' age, stage, and proficiency level" (Rubin, Chamot and Anderson, 2007, p. 156). Second, the principles in selecting target strategies for instruction varied 
among instructional programs, with some focusing on learner needs (Graham \& Macaro, 2008), while others focusing on strategies used by successful learners (Ozeki, 2000; Seo, 2000), which makes it difficult to replicate the studies in different instructional settings. Third, the degree of teacher modelling and scaffolding varied among instructional programs and there lacked a detailed description of such support (Graham \& Macaro, 2008), because "strategy instruction should include sufficient scaffolding, modelling, practice, and development of self-assessment” (Rubin, Chamot, \& Anderson, 2007, p. 160).

\section{Conclusion}

By now, we have examined the two essays from different perspectives of the four linguistic resources, respectively Theme choice, Thematic progression pattern, hyper-Theme and Reporting style. We have identified starkly divergent linguistic choices in the above four areas. In Theme choice, the stronger essay demonstrates considerable expertise in manipulating different types of Themes, especially for textual and interpersonal purposes. However, the weaker essay leans heavily on unmarked topical Theme, which makes it more descriptive rather than evaluative. In Thematic progression, the stronger essay shows a clear logical pattern of Theme progression, while the weaker essay is often unpredictable in Theme progression. In hyper-Theme, the stronger essay is characterized by clear overall organization at the level of paragraph and text through utilization of hyper-Themes, while the weaker essay is loose in logical connection between hyper-Themes. All the above findings indicate that the flexibility in utilizing Theme resources (Theme choice, Thematic progression pattern, hyper-theme) contributes to criticality in textual organization. Likewise, in reporting style, the stronger essay enjoys high frequency of citation and mainly employs non-reporting style to enable evaluation of references, while the weaker essay is relatively sparse in citation and employs more central reporting. This proves non-reporting style as potential in creating criticality in evaluation, while central reporting as possibly responsible for "shopping-list" review. Therefore a structural-functional relationship between the above linguistic resources and criticality in academic writing is established.

Some valuable implication can then be drawn. By making explicit the linguistic realization of criticality, this study helps students better understand assignment instruction and teachers' comment on criticality issues, and informs teachers in academic writing. By demonstrating a discourse study of student essays with the method of rich feature analysis (informed by SFL), this study provides teachers and researchers with a new perspective of research: "criticality".

Limitations of this study are also obvious. First, the small corpus of only two essays can be problematic for drawing confident conclusion about the structural-functional relationship between the four discussed linguistic resources and criticality. In addition, "criticality" in academic writing is an elusive concept. The working definition of "criticality" as textual and interpersonal skills as proposed in this essay might not apply to other context. Third, perception of "criticality" can differ among different lecturers, therefore generalization of the study findings should be made with cautions.

\section{References}

Barton, E. (2004). Linguistic discourse analysis: How the language in texts works. In C. Bazerman \& P. Prior (eds.), What writing does and how it does it: An introduction to texts and textual practices (pp. 57-82). Mahwah, New Jersy: Lawrence Erlbaum Association.

Boote, D. N., \& Beile, P. (2005). Scholars before researchers: On the centrality of the dissertation literature review in research preparation. Educational Researcher, 34(6), 3-15. http://dx.doi.org/10.3102/0013189X034006003

Halliday, M. A. K. (1994). An introduction to functional grammar. London: Edward Arnold.

Halliday, M. A. K., \& Matthiessen, C. M. I. M. (1999). Constructing experience through meaning: A language-based approach to cognition. London: Longman.

Hart, C. (1998). Doing a literature review: Releasing the social science research imagination. London: Sage.

Hewings, A. (2005). Developing discipline-specific writing: an analysis of undergraduate geography essays. In L. J. Ravelli \& R. A. Ellis (Eds.), Analysing academic writing: Contextualized frameworks (pp. 131-152). London: Continuum.

Knowles, J., \& McGloin, S. (2007). Developing critical analysis skills in academic writing. Nursing Standard, 21(52), 35-37. http://dx.doi.org/10.7748/ns2007.09.21.52.35.c6595

Martin, J. R. (1992). English text: System and structure. Benjamins: Amsterdam. http://dx.doi.org/10.1075/z.59

Martin, J. R., Matthiessen, C. M. I. M., \& Painter, C. (1997). Working with Functional Grammar. London: 
Edward Arnold.

Pally, M. (2001). Skills development in 'Sustained' content-Based curricula: Case studies in analytical/critical thinking and academic writing. Language and Education, 15(4), 279-305. http://dx.doi.org/10.1080/09500780108666814

Paltridge, B. (2006). Discourse Analysis. London: Continuum.

Paltridge, B., \& Starfield, S. (2007). Thesis and dissertation writing in a second language: A handbook for supervisors. New York: Routledge.

Randolph, J. J. (2009). A Guide to Writing the Dissertation Literature Review. Practical Assessment, Research and Evaluation, 14(13).

Ravelli, L. J. (2005). Signalling the organization of written texts: hyper-Themes in management and history essays. In L. J. Ravelli \& R. A. Ellis (Eds). Analysing academic writing: Contextualized frameworks (pp. 104-130). London: Continuum.

Swales, J. M. (1990) Genre Analysis: English in Academic and Research Settings. Cambridge: Cambridge University Press.

Thompson, G. (2004). Introducing functional grammar. London: Edward Arnold.

Webster's Ninth New Collegiate Dictionary. (1989). Springfield, MA: Merriam-Webster.

\section{Appendix A. Assignment Instruction and Lecturer's Comment}

\begin{tabular}{|l|l|l|}
\hline TEACHER'S INSTRUCTION & $\begin{array}{l}\text { STUDENTS' } \\
\text { GRADE }\end{array}$ & TEACHER'S COMMENTS \\
\hline $\begin{array}{l}\text { You will choose one approach to } \\
\text { listening introduced in the course, i.e. } \\
\text { process-based. Then, drawing on the } \\
\text { relevant research literature, you will } \\
\text { write an essay summarizing that } \\
\text { approach's theoretical focus, related } \\
\text { research, and practical application, } \\
\text { critically appraise these components of } \\
\text { the approach in general, and discuss } \\
\text { how easy or difficult it would be to } \\
\text { implement this approach in practice in } \\
\text { your teaching context and why. }\end{array}$ & $\begin{array}{l}\text { B- } \\
\text { (Weaker essay) }\end{array}$ & $\begin{array}{l}\text { This is a really good essay. You define the key concepts of a process-based } \\
\text { approach to L2 listening. What is most impressive is your critical appraisal } \\
\text { of the field, and the way in which you integrate all those references. Please } \\
\text { check some of my specific comments and suggestions below. There are also } \\
\text { some minor errors in formatting and expression but on the whole, you write } \\
\text { very well. It is clear to me that you have a sound understanding of L2 } \\
\text { listening pedagogy. }\end{array}$ \\
\hline
\end{tabular}

\section{Appendix B. Dynamic View of the Stronger Essay: Logico-Semantic Relations via Hyper-Theme}

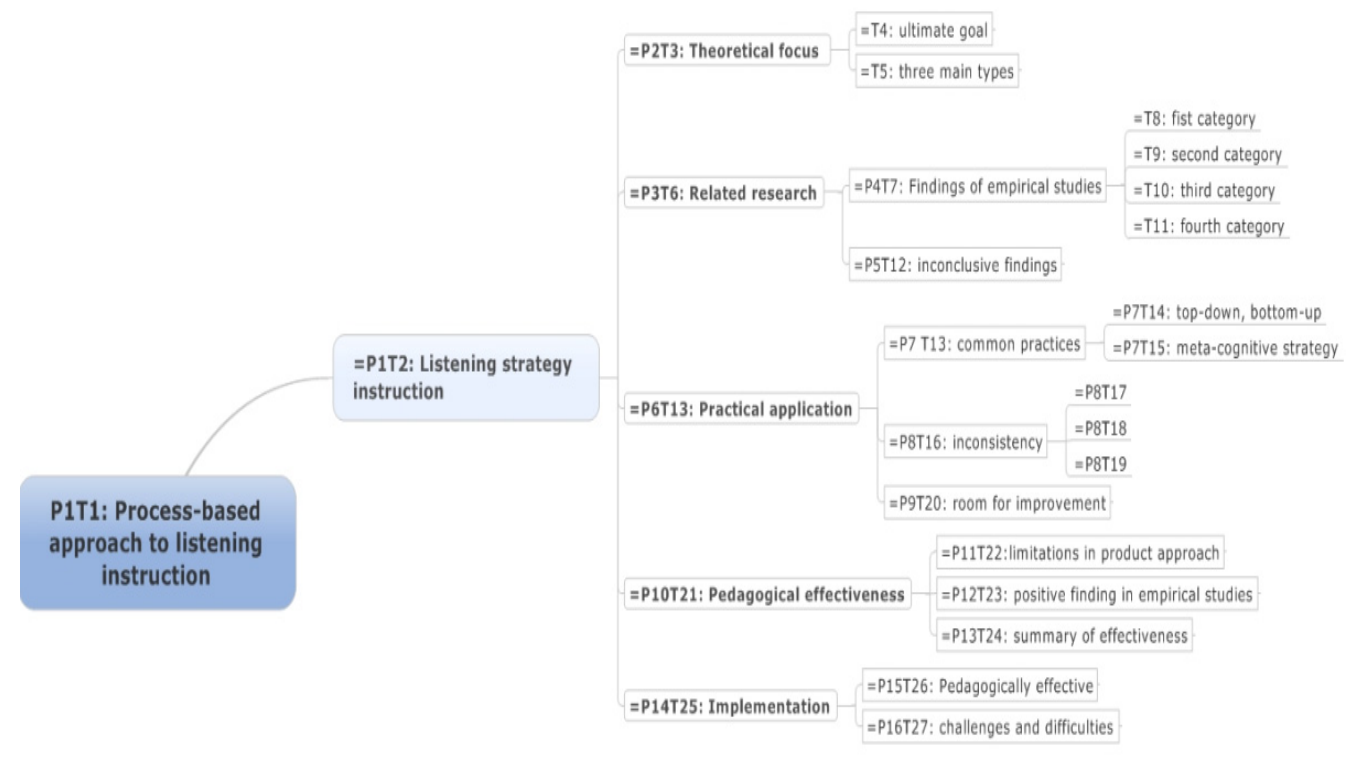




\section{Appendix C. Stronger essay}

\section{On process-based approach to listening instruction ----focusing on listening strategy instruction}

\section{Introduction}

Process-based approach to listening instruction focuses on meaning constructionthrough the interaction of both top-down and bottom-up processing (Goh, 2002), as in contrast to product-based approach where instruction is "based entirely upon the achievement of comprehension tasks" (Field, 2003, p. 325) "with no attempt at training the learners how to go about getting at the meaning" (Mendelsohn, 2006, p. 76), and it consists of two general sub-categories, including bottom-up skills instruction and strategy instruction. This paper will confine the discussion of process-based approach to listening instruction into listening strategy instruction, which broadly means that strategy instruction is "injected" into the existing listening curriculum and has been taken as a root in listening class (Mendelsohn, 2006, pp. 81-82).

\section{Theoretical focus of listening strategy instruction}

Grounded within the theory of cognitive psychology and information processing (Cross, 2009, p. 153), listening strategy instruction focuses on the instruction of "learning to listen", representative of process-based approach to listening instruction (Vandergrift, 2004, p. 3), through the modelling of a cluster of listening strategies that are involved in both top-down and bottom-up processing (Cross, 2009, p. 154) which work interactively to help learners to construct meaning (Goh, 2002) in "both compensatory and confirmatory" manner (Graham and Macaro, 2008, p. 749). The ultimate goal of such an approach is "to empower students by allowing them to take control of the language learning process (Cohen, 1998, p. 70) and to encourage learners' self-involvement and leaning autonomy (Morley, 1993, p. 120). Generally speaking, three main types of listening strategies have been widely documented in the relevant literature and have been commonly adopted in listening strategy instructional programs, including meta-cognitive, cognitive and social-affective strategies (Chamot, 1995), which "help students keep themselves on track", "provide the necessary intellectual tools", and "offer continuous emotional and interpersonal support" respectively (Oxford, 1993, p. 22).

\section{Related research of listening strategy instruction}

Review of literature indicates that the chief concern of strategy-based approach to listening instruction was centred on the effectiveness of such instruction on learners' listening development, chiefly influenced by its theoretical focus mentioned above. Empirical studies about the effect of listening strategy instruction were largely intervention studies where performance of the experimental and control groups was compared before and after the intervention through a pre-test $\&$ post-test design, and those empirical studies have demonstrated a simple but mixed picture.

Findings of empirical studies can be generally classified into four categories. The first category was represented by O’Malley, Chamot, Stwwner-Manzanares, Kupper, and Russo (1985) and Schwartz (1992) who found no significant effect of strategy instruction on learners' listening ability. The second category was represented by Chen (2005) who focused on investigating barriers that hindered learners' development of listening ability within strategy instructional program. Barriers including learners' internal factors and those related to listening strategy and materials were reported. The third category was represented by Ozeki (2000) and Seo (2000) who reported learners' improvements in the use of meta-cognitive and bottom-up strategies. The fourth category reported positive findings about the effect of strategy instruction on learners' listening ability (Cross, 2009; Graham \& Macaro, 2008; McGruddy, 1995; Paulauskas, 1994; Thompson \& Rubin, 1996) in view of the statistically significant differences in listening scores between the experimental and control groups.

Findings from those empirical studies seem to indicate that listening strategy instruction has produced certain positive effects in terms of learners' listening ability and strategy use. However, due to the small number of empirical studies so far and the inconsistent findings they have reported, it cannot be confidently concluded that "this kind of strategy training works" (Field, 1998, p. 115).

\section{Practical application of listening strategy instruction}

Despite the inconclusive findings so far, practitioners are interested in "designing and implementing instructional programs to promote strategy development and use", especially for less proficient listeners (Cross, 2009, p. 154). Therefore, practical application of strategy instruction chiefly focuses on guidelines and principles in its actual implementation, and certain common points have been identified. First, preference in listening strategy instruction was chiefly given to those that are involved in top-down processes, even though those involved in bottom-up processes were also taken into account (Cross, 2009, p. 154). Second, meta-cognitive strategy was 
unanimously included within strategy instructional programs due to the fact that it has been found to be "vital for effective comprehension" (Rubin, Chamot, \& Anderson, 2007, p. 182), even though all the three types of learning strategies need to be taught and practiced (Mendelsohn, 2006, p. 80). While the above two points are commonly adopted practices in listening strategy instructional program, there are also areas where inconsistency were found among those programs. First, few instructional programs have demonstrated "how strategies have been tailored to meet learners' age, stage, and proficiency level" (Rubin, Chamot, \& Anderson, 2007, p. 156). Second, the principles in selecting target strategies for instruction varied among instructional programs, with some focusing on learner needs (Graham \& Macaro, 2008), while others focusing on strategies used by successful learners (Ozeki, 2000; Seo, 2000), which makes it difficult to replicate the studies in different instructional settings. Third, the degree of teacher modelling and scaffolding varied among instructional programs and there lacked a detailed description of such support (Graham \& Macaro, 2008), because "strategy instruction should include sufficient scaffolding, modelling, practice, and development of self-assessment" (Rubin, Chamot, \& Anderson, 2007, p. 160). In a word, there are rooms for further improvement for the implementation of listening strategy instruction, which need to take findings of relevant research into account.

\section{Critique of listening strategy instruction}

Based on the above discussion of the theoretical focus, relevant research and practical application of listening strategy instruction, it is believed that it will be pedagogically effective to integrate strategy instruction into listening curriculum.

First, limitations in the product-based approach to listening instruction necessitate the adoption of a process-based approach, which, therefore, theoretically guarantee the legitimacy of listening strategy instruction. The comprehension-based techniques as incorporated within the product-based approach have been argued as testing listening rather than teaching listening (Mendelsohn, 2006), while a strategy-based approach that focuses on the learning process of listening can help to overcome such shortcoming.

Second, positive findings from empirical studies have provided strong proofs about the effectiveness of listening strategy instruction. Although empirical studies about the effect of listening strategy instruction have produced mixed results, a deeper analysis of the research designs and methodologies used in those studies helps to uncover the reasons for the absence of positive results. Factors such as short intervention time, inexperienced teacher in instructional program, and the use of quantitative research instruments have jointly hindered the emergence of positive results. Therefore, it is believed that listening strategy instruction will be effective in promoting students' learning ability in the long run, in view of the positive findings reported so far, if care could be given to overcome the above mentioned factors in the future.

In a word, although there were concerns about the effectiveness of listening strategy instruction such as its unrealistic expectation and barriers in implementation (Cross, 2009, p. 154), I think its root foundation within cognitive psychology and information processing theory (Cross, 2009, p. 153), its positive findings from empirical studies (e.g. McGruddy, 1995) and the pedagogical implications that have been provided for practical applications in listening class have sufficiently demonstrated its feasibility and effectiveness in actual implementation.

\section{Implementing listening strategy instruction at my home university}

As for the implementation of strategy-based approach to listening instruction at my home university, I think it will be pedagogically effective and feasible, but it will be very difficult at the beginning, considering the instructional situation and school policy. Incorporating listening strategy instruction at my home university will be pedagogically effective for improving my students' listening ability in view of its theoretical basis (Cross, 2009) and positive findings of empirical studies which have demonstrated its conduciveness to learners' listening development (e.g. Graham \& Macaro, 2008). Besides, it will also be feasible to implement such instructional program in view of the number of instructional programs that have been conducted (Seo, 2000). However, it will meet certain challenges and difficulties at the beginning of its implementation.

First, incorporating listening strategy instruction will put higher demands for English teachers who lack theoretical knowledge and practice in training listening strategy. This will require more training programs, which is hardly available for them. Second, it involves a change in current instructional curriculum, which needs to get permitted by the dean of the English Department and Office of Teaching Affair. Change in policy always takes time to achieve, since those responsible for policy-making always do not specialize in teaching methodology. Third, it is not so practical to conduct systematic strategy training in listening class and to take up normal instructional time where students are under pressure to finish their assignment, since listening class typically takes up two hours a week at my university and students have to finish the assignment tasks online, which leaves 
very little time for strategy instruction.

(References: Omitted)

\section{Appendix D. Weaker essay}

\section{Process-based approach in L2 listening classroom: \\ theory, practice and reflection}

Listening is the most essential component of L2 basic learning skills and it also plays a vital role in L2 acquisition. It is considered the first stage of linguistic input for L2 learners but is the least researched area of the four language skills (Vandergrift, 2007). Vandergrift (2007) also indicates that it is not adequate to correctly answer the listening comprehension questions (product), which can hardly help students better understand the listening process. The learners who have a better understanding of the listening process can enhance their listening comprehension. This paper will mainly deal with the theoretical focus of process-based approach, its practical application and critical reflection.

\section{Theoretical focus and related research}

L2 Listening is a skill, a product but above all, a mental process. According to J. R. Anderson (1995), listening is a comprehension process and consists of three levels of processing: perception, parsing and utilization, which serve a cognitive model for listening comprehension. For listeners, background knowledge, knowledge of situation and co-text and knowledge of the language system are considered the three essential sources of information in listening comprehension (Anderson \& Lynch, 1988). And the listening process focuses mainly on meaning not form. In the discussion of L2 listening, "bottom-up" and "top-down" are usually regarded as the two important concepts of listening process. "Bottom-up" refers to that the processing is built from the small units to larger ones, and "top-down" is the process built from the larger units to small ones. In the research made by Hulstijn (2003), "bottom-up" is connected with multimedia software offering three listening modes for listeners to concentrate the separate units or short chunks first and then combine them and interpret the meaning of what they hear.

From the cognitive perspective, listening comprehension strategies provide significant means as the strategy-approach for learners to process information. Chamot (1995) proposed three types of listening strategies: cognitive, metacognitive and social-affective, which have been testified by Chamot (2005) to show that the strategies listeners used help them better understand what they have heard in the listening process and strategy-based instruction can help develop listeners' consciousness of effective use of listening strategies, such as prediction and inferencing. The first two strategies are significant in classroom learning and instruction and communication outside classroom in the target language. Metacognitive strategy might be the most studied among the three categories. It is defined by Chamot $(1995, \mathrm{p} 15)$ as "executive processes associated with the regulation and management of learning, and include strategies used to plan for a task, to monitor a task in progress, and to evaluate the success of a task after its completion". It functions as an approach to "manage and facilitate mental process and cope with difficulties during listening" (Goh, 2002, p7). The metacognitive processes proposed by Vandergrift (2004) give the learners insight into the strategies they should employ while listening and also help them integrate the strategies as a whole. Based upon the definition of metacognition which was integrated "metacognitive strategies" by Brown (1978) and "metacognitive knowledge" by Flavell (1979), Goh (2008) proposed the approach of "metacognitive instruction" which integrated process-based metacognitive awareness with strategy instruction to enhance L2 listening development and help listeners build strategic knowledge in effective and successful listening. Vandergrift (2007) put forward a more process-based instruction to develop the metacognitive knowledge to help listeners foster the awareness of using metacognitive strategies in their listening.

\section{Practical application}

Appropriate use of the listening strategies can enhance learners' listening proficiency, especially the metacognitive strategies, which can unconsciously develop learners' ability to use appropriate strategies and raise their awareness of listening as a process. Nathan (2008) has explored that in listening tasks collaboration impeded a positive influence on the learners' development and understanding of metacognitive knowledge about listening. Goh (2008) combined the person, task and strategic knowledge with planning, monitoring and evaluating, and then formed metacognitive instruction, which has been researched by many scholars. Based upon statistics, the study made by Vandergrift (2007) shows that metacognitive instruction greatly improves learners' listening performance. 
According to Veenman's (2006) three crucial principles for effective metacognitive instruction, two kinds of activities could be employed in the listening classroom: "integrated experiential listening tasks" and "guided reflections on listening" (Goh, 2008). The first task could be used in the schools that class activities conducted follows the textbooks or materials which advocating metacognitive instruction for the listening course. In daily listening classroom, students are immersed in the metacognitive materials and activities, which may help promote the understanding of various listening process and strategies they need to adopt. Gradually, students' awareness of development of metacognitive listening strategies will be enhanced so as to facilitate them with metacognitive knowledge and also develop their self-learning abilities outside the classroom. In this task, the perception exercise, for instance, is an effective way to increase students' listening comprehension by enabling them to pay attention to the difference between different phonological features when they don't have a heavy listening load. It is particularly suitable for beginners and it may "depend largely on bottom-up processing" (Goh, 2002, p. 41). Students will have a better understanding about the task by noticing the phonological variations, the nature and the demands of listening in target language and help them cultivate their processing ability during listening.

The second task aims at encouraging students to form new knowledge by inspiring their prior knowledge about listening when dealing with the listening comprehension on their own. Students think back on what they have heard in the listening task or write down the reflection, manage to plan in advance and accordingly seek the appropriate strategies to improve their own listening proficiency. Keeping a listening diary is more effective in students' own listening experience to help develop "a greater sense of responsibility for their learning" (Goh, 2002, p38). By reflecting and critical thinking on the listening activities they have take part in, students analyze the strengths and weaknesses they have during listening and explore the correct approach or strategies suitable for them to improve their listening comprehension. This activity can also offer students time and space to express pressure, anxiety, terrible feelings on the tediousness of listening tasks. Teachers are encouraged to make students' reflection regular by giving them questions to ponder and respond.

The two metacognitive listening tasks have great impact on the development of students' self-regulation and self-observation of comprehension of listening process. Above all, it enhances students' motivation in listening. When they benefit from metacognitive strategies, they will be greatly motivated to continue the listening and become more hard-working. What teachers need to do is to help students form "a habit of mind that is metacognitively alert and responsive to learning" (Goh, 2008, p. 200).

\section{Reflection}

In general, compared with the product-based approach, the process-based approach is more easily accepted, widely-adopted and significantly influenced listening approach. Specifically, the two approaches of processing of "bottom-up" and "top-down" mainly focus on meaning of listening information rather than the form of it. This, to some extent, may neglect the importance of language form because in fact listeners could not only comprehend the meaning but also get familiar with the sentence patterns or oral expressions at the same time in a listening task. On the other hand, when listeners and teachers emphasize the specific strategies they should use in the listening process, they tend to overlook the influence of social and affective factors on their listening comprehension. As for the disadvantages of the strategies, students may become bored or tedious in using them. For example, they may write listening diaries several times, but it may be hard for them to make it a habit for a long time.

The process-based approach discussed above is what my home university is employing now in our listening curriculum. Among the listening strategies, cognitive strategies may be the most adopted in everyday classroom teaching, while the metacognitive and social-affective strategies are often neglected by most of the teachers. In my university, teachers usually follow the three steps of teaching listening: "pre-listening", "while-listening" and "post-listening" procedures, which are also prevalent in most listening classrooms. Teachers put most of their effort in the pre-listening phase, and they make students well-prepared both mentally and physically by conducting classroom activities such as brainstorming and guessing. And the other two parts are paid little attention. The strategy teachers mainly adopt is prediction which is often used in pre-listening part. It seems that exam-oriented teaching of listening emphasizes more on student's "hard-working" and testing ability than the real strategies they need to enhance their listening ability, which unconsciously makes teachers so passive in listening teaching that they would rather pay much attention to the result than the process of listening. Another reason is probably that most teachers haven't been trained how to teach listening with strategies.

To sum up, process-based listening approach has been developed for many years. The three types of listening strategies listed by Goh (2002a) gives us a very good insight into the listening process itself, and facilitate with 
teachers the specific activities teachers can use in their teaching circumstance. Teachers need to be familiar with the approaches, strategies and the principles of listening instruction in order to help students enhance their listening ability and be motivated and self-regulated in their own listening experience.

(References: Omitted)

\section{Copyrights}

Copyright for this article is retained by the author(s), with first publication rights granted to the journal.

This is an open-access article distributed under the terms and conditions of the Creative Commons Attribution license (http://creativecommons.org/licenses/by/3.0/). 